\title{
AOR
}

Selected Papers of \#AoIR2019:

The $20^{\text {th }}$ Annual Conference of the

Association of Internet Researchers Brisbane, Australia / 2-5 October 2019

\section{Data Selves: Trust, Control and Self-Representation in Digital Society}

\author{
Brady Robards \\ Monash University \\ Benjamin Lyall \\ Monash University \\ Claire Moran \\ Monash University \\ Jean Burgess \\ Queensland University of Technology (QUT) \\ Kath Albury \\ Swinburne University of Technology \\ Rowan Wilken \\ Royal Melbourne Institute of Technology (RMIT) \\ Anthony McCosker \\ Swinburne University of Technology \\ Terri Senft \\ Macquarie University
}

A considerable amount of personal data is now collected on and by individuals: footsteps on Fitbits, screen time in Apple's iOS, conversations on dating apps, sleeping patterns in baby tracker apps, and viewing habits on Netflix and YouTube. What value do these data have, for individuals but also for corporations, governments, and researchers? When these data are provided back to users, how do people make sense of it? What 'truth claims' do quantified personal data make? How do we navigate

Suggested Citation (APA): Robards, B., Lyall, B., Moran, C., Burgess, J., Wilken, R., McCosker, A. \& Senft, T. (2019, October 2-5). Data Selves: Trust, Control and Self-Representation in Digital Society. Paper presented at AolR 2019: The 20 $0^{\text {th }}$ Annual Conference of the Association of Internet Researchers. Brisbane, Australia: AolR. Retrieved from http://spir.aoir.org. 
anxieties around datafied selves, and in what ways are bodies rendered visible or invisible through processes of datafication in digital society?

In this panel we explore these questions through four papers centered on the notion of the "data-selfie." Data-selfies take different forms, including but not limited to:

- Visuals that reference the "status" or "progress" of a user's physical body, as in 3-D scans, or charts generated by self-monitoring apps for health and fitness.

- Visuals that reference the remapping of photographic self-expression to biometric, corporate and state surveillance, such as airport facial recognition check points that ask flyers to pose for a selfie, or sex offender databases that now contain images first posted to hook up apps by consenting teenagers.

- Representations of the embodied or commoditized self, produced not as standalone expression, but as conversational prompts that encourage qualitative, "story-driven" data, in the interests of pedagogy, therapy, activism, etc.

- Profiles that reference users as "targets" whose chief value is the metadata they generate. Using proprietary algorithms, platforms mine this metadata-which can include information about a users' device, physical location, and their activities online-categorizing it for internal use, and selling it to third parties interested in influencing the consumer, social and/or political preferences of the "targets" in question.

In Paper 1, Robards, Lyall and Moran develop a new conceptualisation for understanding how individuals reveal themselves through their own quantified personal data. They call this the 'confessional data selfie'. Drawing on a sample of 59 examples from the top posts in subreddit $r /$ DatalsBeautiful, they argue that the confessional data selfie represents an aspect of one's self, through visualisations of personal data, inviting analysis, eliciting responses and personal story-telling, and opening one's life up to others.

In Paper 2, Burgess, Albury and Wilken take a political economy of communication approach to analyse the data markets of dating apps. They consider three cases: Grindr, Match Group (parent company of Tinder), and Bumble. Drawing on trade press reportage, financial reports, and other materials associated with the apps and publishers in question, they point to the increased global concentration in ownership of dating app services and raise questions about the ways in which dating apps are now in the 'data business', using personal data to profile users and monetise private interactions.

In Paper 3, McCosker reports on experiences of 'data anxiety' among older people in Australia. McCosker draws on data literacy workshops, home-based interviews and focus groups with older internet users, that led to discussions of control over personal data, control over social interactions, and the resulting implications for exposure, openness, and visibility. Also key to this study was the taking and sharing of selfies in a closed Facebook group, serving as the starting point for reflections on these various experiences of control. Many of these older participants questioned whether or not ongoing participation in social media and broader data structures were 'worthwhile'. This raises broader questions about the extent to which users are willing to sacrifice 
control over personal data - or the feeling of control - in order to participate and be visible.

Finally, in Paper 4, Senft asks: when is the face data? Moving from examples of 'deepfake' video exhibitions to Google Art as a repository of 'face-data' as cultural and social capital, Senft goes on to examine how notions of face-as-data apply to individuals living with the neurological condition of autism. Can facial recognition apps help people with autism to read and decode human expressions?

Taken together, these four papers each engage with questions about the relationship between personal data and broader structures of power and representation: from corporations like Grindr and Tinder using dating app data to profile users, to Google using uploaded selfies to train facial recognition algorithms; through to re-purposing and narrativising personal data as part of practices of self-representation; and the feelings of anxiety, unease or creepiness that accompany the increased datafication of personal identity. Self-representation is also a key recurrent thread in these papers, from confessional data selfies as acts of revelation through personal quantified data, through to the photographic selfie as a research exercise that prompts discussions of control and data privacy. 


\section{Paper 1 - Confessional Data Selfies}

\section{Brady Robards, Benjamin Lyall \& Claire Moran (Monash)}

'Data selfies' are representations of one's self through typically quantitative data. For example, self-tracking devices from Fitbit and Apple collect data automatically, producing visualisations of activity such as steps taken, hours slept, heart rate, calories burnt, and so on. These data selfies can be shared with friends, as part of a competition, or for personal reflection, but what is common is that they tell a story. In this paper we explore practices around what we are calling 'confessional data selfies' as shared on the reddit forum $\mathrm{r} / \mathrm{DatalsBeautiful}$. On this subreddit, with more than 13 million subscribers, redditors share often complex, intimate, highly detailed quantitative self-representations of their lives, many of which include a confessional quality.

We draw on an analysis of the top 1000 posts made to $\mathrm{r} / \mathrm{DatalsBeautiful}$ as of September 2018. Reflecting on the way data records draw on traditions of Christian confession (Rettberg 2014: 4-6), we identified 59 post that met our definition of a 'confessional data selfie': A visual representation of one's self (or some aspect of one's life), told through quantified data, that reveals or 'confesses' something. To channel Senft and Baym (2015), we asked: what do these confessional data selfies say? We undertook closer analyses of these 59 posts, coding them into twelve categories grouped under three broad themes: routine management, families and relationships, and body rhythms.

Routine management was the biggest group of confessional data selfies $(n=27)$, with 9 selfies revealing technology use (eg. "Network visualization of my twitter followers and their followers. Almost three years after her passing, my late girl friend is still my strongest connection"), 7 on study patterns ("Graph of my GPA per semester in college"), 6 on money and personal finances ("I have been tracking my net worth for more than 3 years during college and after"), 3 detailed 'life-logging' selfies ("Every hour of my 2016 charted by category"), and 2 posts that tracked physical location ("6 Months of where l've spent my nights after starting a new job"). While often mundane, these 'routine' posts matched typical self-tracking practices in creating a data-derived 'mirror for the self' (Lomborg and Frandsen 2016, 1021).

The next two broad themes had an equal number of posts. Data selfies on families and relationships $(n=16)$ were some of the most highly upvoted posts in the subreddit, with 9 on relationships ("Heart rate when my wife asked for a divorce"), 4 on children ("My daughters sleeping patterns for the first 4 months of her life"), and 3 on dating practices ("My 180 Days of Lesbian Online Dating"). We made a distinction between 'relationships' and 'dating' in coding, as posts about relationships usually documented these longitudinally, whereas posts about dating were on (often unsuccessful) courtship experiences. There was considerable cross-over in some categories, such as with this post: "Network visualization of my twitter followers and their followers. Almost three years after her passing, my late girl friend is still my strongest connection". We coded this under technology use, because that was the topic being depicted, but clearly the relationship dimension became integral to this data selfie and its appeal, attracting 26,606 upvotes and 330 comments. According to Lambert (2016: 75), relationship 
tracking (through digitally-quantified means) appropriates psychotherapy by framing emotional analyses as integral to relationship success - but ultimately - fails to link these (83). The subreddit ratifies this argument, and data selfies that confessed or revealed something about a relationship - the agony of separation, the patterns of text message exchange, even word frequency analyses of emails - tended to attract the most upvotes and comments.

Our third and final broad theme was body rhythms $(n=16)$. Within this theme were 9 posts on health ("My weight loss over 126 weeks"), 4 on sleep ("My wife and I finally have my 18 month old on a consistent sleep schedule! Data from the month of April"), 4 on sport ("Failing to run the Paris Marathon under 4:00:00. I've tried to animate how I did..."), and 2 on masturbation ("My Masturbation Habits for the Last 3 Months Visualized"). In many ways, these 'body rhythm' posts are typical of expressions of mainstream fitness-tracking practices in the era of the 'second fitness boom' (Millington 2016): A boom mediated by digital technologies like apps, exergames and wearables, which reify self-discipline under 'healthist' discourses. In these data selfies, bodily selfsurveillance meets 'risk' and becomes a moral concern (Esmonde \& Jette, 2018: 2), further adding to the confessional nature of personal disclosures (Reigeluth 2014, 252; Fotopoulou 2018, 150) on r/DatalsBeautiful.

A significant finding from our analysis of these data selfies is the heavily gendered nature of the subreddit and the confessional data selfie as a practice. Only $8 \%$ of the data selfies in our sub-sample of 59 were clearly women $(n=5)$. Most data selfies were by men $(n=38)$, a further 9 were coded as 'probably men', and there were 6 posts where we were unable to discern gender. We ask: In what ways might the confessional data selfie be accessible to men in ways that photographic selfie-work has been coded as feminine? (see, for instance, Tiidenberg \& Cruz 2015).

The confessional data selfie appears to attempt to present its author in a kind of unbiased, 'self laid bare', transparent way. The confessional data selfie represents an aspect of one's self, invites analysis, elicits responses and personal story-telling, and following the style of the Quantified Self networked publics (Smith and Vonthethoff, 2016) - opens one's life up to others. In theorising the confessional data selfie, we follow Senft and Baym (2015: 1595), who themselves draw on Frosh (2015), to suggest that "rather than inviting voyeurism, selfies show a "self enacting itself" and invite spectators to reflect on the "very instability of the term 'self"... selfies invite viewers to think of identity "between the self as an image and as a body, as a constructed effect of representation and as an object and agent of representation"'.

\section{References}

Esmonde, K. \& Jette, S. (2018) Assembling the 'Fitbit subject': A Foucauldiansociomaterialist examination of social class, gender and self-surveillance on Fitbit community message boards. Health. doi: 10.1177/1363459318800166

Fotopoulou, A. (2018) 'From networked to quantified self: Self-tracking and the moral economy of data in A Networked Self and Platforms, Stories, Connections ed. Zizi Papacharissi. New York: Routledge: 144-159. 
Frosh, P. (2015) 'The gestural image: The selfie, photography theory, and kinesthetic sociability', International Journal of Communication, 9(2015): 1607-1628.

Lambert, A. (2016) Bodies, mood and excess: Relationship tracking and the technicity of intimacy. Digital Culture and Society 2(1): 71-88. doi: 10.14361/dcs-2016-0106

Lomborg, S \& Frandsen, K (2016) 'Self-tracking as Communication'. Information, Communication \& Society 19(7): 1015-1027. Doi: 10.1080/1369118X.2015.1067710

Millington, B. (2016) Fit for prosumption: Interactivity and the second fitness boom. Media Culture and Society 38(8): 1184-1200. doi: 10.1177/0163443716643150

Reigeluth, T. (2014) Why data is not enough. Surveillance and Society 12(2): 243-354. doi: $10.24908 /$ ss.v12i 2.4741

Tiidenberg, K. \& Cruz, E. G. (2015). Selfies, Image and the Re-making of the Body. Body \& Society, 21(4), 77-102. https://doi.org/10.1177/1357034X15592465

Rettberg J W (2014) Seeing Ourselves Through Technology. Hampshire: Palgrave Macmillan.

Senft, T. \& Baym, N. (2015) 'What does the selfie say? Investigating a global phenomenon', International Journal of Communication, 9(2015): 1588-1606

Smith, G. \& Vonthethoff, B. (2017) Health by numbers? Exploring the practice and experience of datafied health. Health Sociology Review 26(1): 6-21. doi:

10.1080/14461242.2016.1196600 


\section{Paper 2 - Dating apps as data markets}

\section{Jean Burgess (QUT), Kath Albury (Swinburne) \& Rowan Wilken (RMIT)}

Numerous and widely used, dating apps collect and connect detailed personal data across platforms - they might use Facebook for authentication; import images from Instagram; and integrate cultural consumption data from Spotify, for example. They are therefore important actors in the digital media environment's broader logics and economies of datafication (Helmond 2015). They are a key site of user data commodification (Steheling et al. 2018), and also of user creativity and resistance with respect to data cultures (David \& Cambre 2016; Wang 2018; Zhao 2018). However, as yet we know remarkably little about the corporate structures behind these apps, how economic value is attributed to and extracted from dating app data, and how these data are monetized.

In addressing this gap, we build on the established and well-tested political economy of communication approach (Hardy 2014; Janet Wasko 2004; Mosco 1996), which has been applied not only to the analysis of regulated broadcast media industries, but has already also been partially adapted to addressing the distinctive challenges of studying search, mobile, locative, and social media industries (van Couvering 2011; Goldsmith 2014; Frith 2015; Albarran 2013). We apply it to the data markets of dating apps by examining three cases: Grindr; Match Group (parent company of Tinder); and Bumble. We draw on trade press reportage (Corrigan 2018), financial reports, and a range of ancillary materials associated with the apps and publishers in question.

Each of these three firms is at a different stage of development (Grindr and Match Group are established businesses; Bumble is a growth-phase start-up) and they operate at different scales (Grindr and Bumble are stand-alone businesses, Match Group is a large, publicly listed parent company). However, they converge when it comes to revenue generation: all of them rely in some way on the monetization of user data, including through data profiling and targeted advertising as part of their "freemium" business models - various combinations of advertising-supported free services and paid subscription services. Our examination of Grindr and Bumble also highlighted a subtle trend toward diversification into data-driven media and lifestyle services. Through data-mining and analysis of chat transcripts, Grindr was able to identify that its subscribers were using the app for social purposes other than organising hook-ups, e.g. seeking travel and accommodation advice, and general socialising. Bumble, meanwhile, pursued what it refers to as an "omni-channel approach" by offering data-reliant "friendfinder" functions and business contact matching (becoming the "Linked-In for Women").

Our analysis of these cases also reveals increased global concentration in ownership of dating app services, which is dominated by Match Group, Spark Networks, Global Personals, The Meet Group, and Badoo, mirroring trends in social media ownership more broadly. We observe a trend towards the accumulation of large, diverse portfolios of dating apps from which user data can be extracted, aggregated, and used for microtargeting of ever smaller niches - a sign that such companies are increasingly in the data business as much as they are in the dating services business. This emerging business model seeks to capitalise on post-demographic processes of market 
segmentation, whereby dating app platforms (and their parent companies) "work to multiply, quantify and in turn deepen processes of segmentation by incremental adjustments to interface design, affordances and subsequent cultures of use" (McCosker 2017), as well as through their overall suite of offerings. Understanding these issues is vital if we are to make sense of the data markets that form around dating apps, understand the implications of the monetization of and trade in such highly sensitive personal data, and help to enhance public understanding of these developments.

The paper concludes by sketching out some of the ways that our political economy of dating services approach can also be usefully integrated with app and software studies more generally. Already, various interface methods approaches (Dieter et al. 2018; Light et al. 2018; Møller Jørgensen 2016) involve not only the close reading and critical analysis of design features and logics, but also an investigation of the app's "environment of expected use," including its operating model, which would be significantly enhanced by the inclusion of a political economy of data markets, data sharing, and business ownership structures. Drawing on our experience in conducting projects that engage directly with dating app users, we show how the identification and analysis of such data structures and flows is not only useful for critical scholars, but can also can be integrated with participatory research activities - such as mapping 'data journeys' (Bates et al 2016) - that aim to uncover the 'data selves' that are constructed and exploited by dating apps, and to enhance data literacies among ordinary users.

\section{References}

Albarran, Alan B. (ed.), The Social Media Industries. New York: Routledge, 2013.

Bates, Jo, Yu-Wei Lin, and Paula Goodale. "Data journeys: Capturing the socio-material constitution of data objects and flows." Big Data \& Society 3.2 (2016): 2053951716654502.

Corrigan, Thomas F. "Making Implicit Methods Explicit: Trade Press Analysis in the Political Economy of Communication." International Journal of Communication 18 (2018): 2751-2772.

David, Gaby, and Cambre, Carolina, "Screened Intimacies: Tinder and the Swipe Logic". Social Media + Society 2, no. 2 (2016): 1-11.

Dieter, Michael, Gerlitz, Carolin, Helmond, Anne, Tkacz, Nathaniel, van der Vlist, Fernando, and Weltevrede, Esther, "Store, Interface, Package, Connection: Methods and Propositions for Multi-situated App Studies." Working Paper Series | No. 4 | 2018 Collaborative Research Center 1187 Media of Cooperation.

Frith, Jordan, Smartphones as Locative Media. Cambridge: Polity, 2015.

Goldsmith, Ben, "The Smartphone App Economy and App Ecosystems." In The Routledge Companion to Mobile Media, edited by Gerard Goggin and Larissa Hjorth, 171-180. New York: Routledge, 2014. 
Hardy, Jonathan. Critical Political Economy of the Media. London: Routledge, 2014.

Helmond, Anne, "The Platformization of the Web: Making Web Data Platform Ready." Social Media + Society (2015). https://doi.org/10.1177/2056305115603080

Light, Ben, Burgess, Jean, \& Duguay, Stefanie. "The walkthrough method: An approach to the study of apps." New Media \& Society 20, no. 3 (2018): 881-900.

McCosker, A. (2017). Data literacies for the postdemographic social media self. First Monday 22(10): https://uncommonculture.org/ojs/index.php/fm/article/view/7307

Møller Jørgensen, Kristian, "The Media Go-along: Researching Mobilities with Media at Hand." MedieKultur: Journal of Media and Communication Research 60 (2016): 32-49.

Steheling, Miriam, Vesnic-Alujevic, Lucia, Jorge, Ana, and Maropo, Lidia, "The Cooption of Audience Data and User-Generated Content: Empowerment and Exploitation Amidst, Produsage and Crowdsourcing." In The Future of Audiences: A Foresight Analysis of Interfaces and Engagement, edited by Ranjana Das and Brita Ytre-Arne, 7999. Heidelberg: Springer, 2018.

Van Couvering, Elizabeth, "Navigational Media: The Political Economy of Online Traffic." In The Political Economics of Media: The Transformation of the Global Media Industries, edited by Dwayne Winseck and Dal Yong Jin, 183-200. London: Bloomsbury Academic, 2011.

Wang, Shuaishuai, "Calculating Dating Goals: Data Gaming and Algorithmic Sociality on Blued, a Chinese Dating App." Information, Communication \& Society (2018). doi.org/10.1080/1369118X.2018.1490796

Wasko, Janet, "The Political Economy of Communication." In The SAGE Handbook of Media Studies, edited by John Downing, Denis McQuail, Philip Schlesinger, and Ellen A. Wartella, 309-329. Thousand Oaks, CA: Sage, 2004.

Zhao, Bo, "Detecting Location Spoofing in Social Media: Investigations of an Emerging Issue in Geospatial Big Data," 2018, Dissertation Presented in Partial Fulfillment of the Requirements for the Degree Doctor of Philosophy in the Graduate School of The Ohio State University, Graduate Program, Ohio State University, USA. 


\section{Paper 3 - Ageing with digital technology: Data literacies and heuristic selfies}

\section{Anthony McCosker (Swinburne)}

As the downside to the increasing value and burgeoning collection of personal data from internet use, data anxiety defines and, in many ways, shapes the digital participation and literacies gap disproportionately affecting older people. This paper reports on part of a research project with older internet users that aimed to better understand differences in use and literacies - an emerging 'participation divide' related to uneven outcomes of internet use (Davis et al., 2018; Hargittai and Walejko, 2008).

Older internet users face particular challenges to digital inclusion that are not well understood. Our project devised a method for developing digital literacies that focused on use of social media and digital storytelling. In the process we uncovered the central importance that data anxiety plays for reluctant older internet users. We worked with groups in two local government areas in Melbourne, Australia ( $n=22$, average age 73).

The core aim was to both articulate and intervene in tensions around agency, control and social identity in the face of growing data anxiety amongst older internet users. This paper targets the specific question: what personal data investments are made through the act of engaging with particular platforms and participating in digital society?

In one part of the project, we devised a workshop technique using selfies as a heuristic device - that is, as a means for provoking reflection and discussion about boundaries around social media use and associated data anxieties. This method adapts work by Albury et al. (2017) to use selfies as a discovery tool for understanding tensions regarding social connection and self-presentation. In addition to literacies workshops, research methods involved home-based interviews and focus groups over a threemonth period in 2017.

Participants were grappling to differing extent with low confidence, skills and abilities digital literacies - but also with their capacity to understand, negotiate and control the personal data associated with their newly active use of social media - data literacies. Digital literacy is often understood as an adaptive set of abilities, skills and knowledge about the operation, and cultures of digital media use (Jones and Hafner, 2012; van Deursen and van Dijk, 2010). Because the participants had limited language to express their data anxieties, we used the selfie exercise to surface and interrogate key concerns while building new strategic communication skills.

The notion of data literacies has been defined previously as the capabilities that enable 'individuals to access, interpret, critically assess, manage, handle and ethically use data' (Calzada Prado and Mazal, 2013), but this seems increasingly challenging in our complex and often opaque data environments. What degree of data literacy would enable older internet users or others who are digitally disconnected to better navigate and gain some control over the digital tools and platforms that might benefit them socially and economically? 
Asking workshop participants to take and share selfies to a closed Facebook group helped to isolate and challenge particular tensions, competencies and knowledge about the way social media activity and interactivity is entwined broadly with core platform metrics: profile data, activity and interactivity, and personal visibility, or degrees of publicness (McCosker, 2017). When we explored difficulties with and concerns about social media use in interviews, three main themes emerged. We found that the same mechanisms that drive social media's core metrics, analytics and data-based business model are those that generate the most anxiety for our older participants.

First, and the most common anxiety or difficulty with social media use involved personal data control. This involved concerns about financial information and security, and personal information understood in a range of ways but always concerning control over profile data as a means of controlling access to personal assets. One account captured the tension resulting in reluctance to engage actively online:

It's just the fact that on the one hand I believe in total openness, and on the other hand I believe in being a protector of data. I know the different situations but the different parts of me and I'm reacting quite differently to these circumstances. There's not really a logic to it. It's an instinctive thing. I just say, why do I need to reveal that information about myself? (Henry)

A second common theme involved deep uncertainty about control over interaction. For example:

Well, it's not the fear of social media. It's the fear of the implications of the handle of social media. That I might say something that I wish to be said in private, but other people repeat it. I know you can go private and things like that. But you have no control over what other people may want to repeat. And this is a fear of mine. (Rumbles)

Third, the issue of visibility control concerned two aspects of the flow of information and personal data through active engagement with social media. Many of the participants suggested they had undertaken careful boundary work around exposure of personal or intimate detail through profiles and posts, and remained skeptical of those who they felt gave too much information about their lives. Harry had previously preferred to use WhatsApp or Viber because he felt that Facebook was too public, 'more open'.

When sharing their selfies through Facebook, participants were overwhelmingly focused on how to control access and exposure, the degree of openness, and hence visibility:

It brought it home to me when we did our little workshop just the other day, because - you know how we got onto Facebook, we created an account... When I put my photo up, within half an hour I had five people commenting on the photo. And I thought - hang on a second, I was under the impression that this photo was part of a closed group. (Rose)

While these anxieties are well known and expected of a platform like Facebook, with its complicated privacy settings, controls, and interactions with data brokers and 
advertisers, they connect with core targets of the platforms' data capture strategy, and in the process signal those hard to articulate aspects of personal digital trace and data exposure that are important targets for addressing data literacies and the persistent participation gap. By the end of the workshop program, many participants were still questioning whether their personal investment in these data structures was worthwhile.

\section{References}

Albury, K. et al. (2017) 'The selfie course: More than a MOOC', in Bennett, R. \& Kent, M. (eds). Massive open online courses and higher education. (168-183) London, Routledge.

Calzada Prado, J. and Marzal, M. Á. (2013) 'Incorporating data literacy into information literacy programs: Core competencies and contents,' Libri, 63(2), 123-134.

Davis, H., McCosker, A., Bossio, D., \& Schleser, M. (2018). '60+ Online: Enhancing digital inclusion of seniors via mobile digital stories and social media participation.' The Journal of Community Informatics, 14(1), 38.

Hargittai, E., \& Walejko, G. (2008). 'The participation divide: Content creation and sharing in the digital age.' Information, Community and Society, 11(2), 239-256.

Jones, R. H., \& Hafner, C. A. (2012) Understanding digital literacies: A practical introduction. Routledge, London.

McCosker, A. (2017) 'Data literacies for the postdemographic social media self'. First Monday, 22(10).

van Deursen, A., \& van Dijk, J. (2010) Measuring internet skills. International Journal of Human-Computer Interaction, 26(10), 891-916. 


\section{Paper 4 - When the Face is Data}

\section{Terri Senft (Macquarie)}

What does it mean to trust the face as data? How do we know the judgments we make from this data are accurate or ethical ones? From courtship rituals to courtroom practices, the face has long served as the terrain for battles over trust. Existing academic literature about the face-as-data spreads across the fields of neuroscience, medicine, psychology, sociology, art, business and law. Today, interest has moved into the fields of computational vision, machine learning, interface design, and biometric policy.

This paper attempts to synthesize disparate conversations about desires, anxieties, challenges, and politics we face when conceptualizing face-as-data by way of four theorists of the face, and four contemporary cases: British artist Gillian Wearing's recent "deepfake" video exhibition; Google Art's "selfie" app; a recent effort to use facial recognition technologies to diagnose autism in children; and an app designed to help the $2 \%$ of the world's population who cannot engage in everyday facial recognition.

The paper begins with British artist Gillian Wearing's recent "deepfake" video exhibition, in which she mapped her face to a series of random bodies (Beer, 2018). The commercial appeal of Wearing's project--which contrasts sharply with current political anxiety around deepfakes (Beer, 2018)-requires some unpacking. For this, the paper turns to Erving Goffman's (1967) argument that although the face is experienced as personal property, its primary utility is as a social image. Special attention is paid to Goffman's arguments regarding "face-work" as the social glue to which personal trust and political order adheres.

Continuing the thread of face as social image and artistic currency, the second case this paper explores involves Google Arts \& Culture: a wildly popular phone application that compares selfies uploaded by users to museum portraits in Google Art's database. (Held, 2018) Here, the paper considers how Google Art encourages users to circulate face-data as cultural and social capital, extending Goffman's thoughts on face-work to include "immaterial labor" on the internet. To consider how the selfies used for Google Art comparisons generate fiscal capital (for Google, for social media platforms the app 'results' are posted on?, for third parties purchasing the meta-data generated by users as they upload images), the paper turns to Deleuze and Guattari's (1987) argument that rather than a reflection of subjectivity, the face is better understood as a frame for subjectification under capitalism.

The third and fourth cases in the paper explore how notions of face-as-data affect and apply to individuals living with the neurological condition of autism. This section begins with a project at Duke University that purports to diagnose autism in children by showing them videos on a smartphone and recording their facial reactions (Bates, 2018). It then moves to consider a series of phone apps designed to teach facial recognition: a skill that many members of Autistic community reporting finding difficult or impossible. 
Here, arguments about the face as a site of subjectification are overlaid with the work on Emmanuel Levinas, who theorized the face first and foremost as "representative of our inability to fully capture and control the Other (Black, 2011: 20)." ). Neurologists tell us that we process facial recognition in the amygdala, a part of the brain that also helps establish rapid emotional responses like trust. In child development circles, neurotypical children are often assessed by their ability to recognize faces, which helps them make determinations about which people to trust (Ewing, 2015). They are also expected to reflect these things on their own faces as expression (interest, engagement, etc.) By contrast, the "selfies" of neurologically atypical children (in this case, those with compromised or damaged amygdala) fail to meet these conditions, and their condition is read as lack.

Where the Duke project maps faces to data in the name of diagnosing autism, facial recognition apps help users learn to mimic what 'normal' people experience as natural processes of facial identification-from the face of the Other to the mind of the Other. It can also help us raise interesting questions. There is now a fair amount of research asserting that most people can make accurate social judgements about others in a very short period. However, explains Alexander Todorov, neuroscientists tend to define "accurate" social judgements as those that map to existing social consensus. He reminds us: "The fact that people agree that a person looks untrustworthy does not mean that the person is actually untrustworthy" (Todorov, 2009: 829).

Continuing in the vein of interrogating accepted wisdom, the paper ends by reconsidering what we gain and lose by trusting the face as a singular entity tied to a particular sort of expressive self, rather than a substitutable and communal set of data in the service of what Jodi Dean terms "selfie communism." The paper concludes by considering the activist possibilities of Dean's observation: "To be common and reproducible is a characteristic of each of us, a realization we enact with every selfie and hashtag, even when we may not be fully aware that we are doing it (Dean, 2016)."

\section{References}

Bates, Karl. 2018. "Mobile App for Autism Screening Yields Useful Data Pilot study finds app easy to use, liked by parents." Duke Today. 1 June 1. Online at https://today.duke.edu/2018/06/mobile-app-autism-screening-yields-useful-data

Beer, Jeff (2018) "This new deep fake video is both advertising and a work of art." Fast Company. Online at https://www.fastcompany.com/90279597/this-new-deep-fakevideo-is-both-advertising-and-a-piece-of-art

Black, Daniel (2011) "What is a Face?" Body \& Society. Vol. 17(4): 1-25.

Dean, Jodi (2016) "Images without Viewers: Selfie Communism." 1 February. Foto Liquid Photography Museum. Online at https://www.fotomuseum.ch/en/explore/stillsearching/articles/26420

Deleuze, Gilles and Felix Guattari (1987) A Thousand Plateaus: Capitalism and Schizophrenia, trans. Brian Massumi. Minneapolis: University of Minnesota Press. 
Edkins, J. (2015). Face politics. New York: Routledge

Ewing, L, Caulfied, F. et al. (2015) Appearance-based trust behaviour is reduced in children with autism spectrum disorder. Autism Vol. 19(8) 1002-1009

Goffman, Erving (1959) The Presentation of Self in Everyday Life. New York: Anchor.

Goffman, Erving (1967) "The Face" in Interaction Ritual. New York: Doubleday.

Held, Amy (2018) "Google App Goes Viral Making an Art out of Matching Faces to Paintings." NPR. 15 January. Online at https://www.npr.org/sections/thetwoway/2018/01/15/578151195/google-app-goes-viral-making-an-art-out-of-matchingfaces-to-paintings

Lévinas, Emmanuel and Philippe Nemo (1985) Ethics and Infinity. Duquesne University Press.

Todorov, A. Pakrashi, M. Oosterhof, N. (2009) "Evaluating Faces on Trustworthiness After Minimal Time Exposure." Social Cognition, Vol. 27, No. 6, 2009, pp. 813-833. 